\title{
Generation of Empirical Correlation for Predicting Drag Reduction of Oil-Water Flows with Natural Polymers
}

\author{
1, 2*EDOMWONYI-OTU, LC; ${ }^{2}$ DOSUMU, AI; ${ }^{3}$ YUSUF, $\mathrm{N} ;{ }^{2}$ ABUBAKAR, A \\ ${ }^{I}$ Department of Chemical and Petroleum Engineering, Delta State University, Abraka, Nigeria \\ ${ }^{2}$ Department of Chemical Engineering Ahmadu Bello University, Zaria, Nigeria \\ ${ }^{3}$ Department of Chemical and Petroleum Engineering, Bayero University, Kano, Nigeria \\ *Corresponding Author Email: uceclce@ucl.ac.uk; Tel: +2349099265536
}

\begin{abstract}
There is an increasing need to accurately predict the behaviour of fluid in the different flow geometry as applicable in the industries. The prediction of drag reduction phenomenon observed during the two-phase oil-water flow with drag reducing polymers in horizontal pipes was investigated. The Power law model was adopted in this study to empirically correlate the data acquired from our earlier experimental works in a 12-mm ID and 20-mm ID pipes. The model accurately predicts the drag reduction across the horizontal pipes. The agreement between the predicted and experimental drag reductions was better in the 12-mm ID pipe than in the 20-mm ID pipe. More work and data is needed to enhance the predictive accuracy of applicable models.
\end{abstract}

\section{DOI: https://dx.doi.org/10.4314/jasem.v23i2.2}

Copyright: Copyright (C) 2019 Edomwonyi-Otu et al. This is an open access article distributed under the Creative Commons Attribution License (CCL), which permits unrestricted use, distribution, and reproduction in any medium, provided the original work is properly cited.

Dates: Received: 13 December 2018; Revised: 17 January 2019; Accepted 30 January 2019

Keywords: Drag reduction; polymers; horizontal pipes, oil-water flow, modelling

Liquid-liquid flow through pipeline has many different industrial applications, such as petrochemicals and crude oil pipelines. The liquidliquid flow become very complex in nature and the two important hydrodynamic parameters in the design of directional wells or pipelines are the pressure gradient and holdup (Abubakar, 2016; EdomwonyiOtu et al., 2015). Mechanistic and empirical models can unfailingly predict these parameters, especially pressure gradients. Empirical models are used to predict pressure gradients from available experimental data. Mechanistic models classified as two-fluid and homogeneous models are used to predict the pressure gradients of separated oil-water flow and dispersed oil-water flow respectively (Abubakar, 2016). However, despite numerous experimental, theoretical and simulation approaches in this field, the exact mechanism of drag reduction is still a subject of research and debate (Jiri and Jacqyes, 1997; Kulmatova, 2013; Edomwonyi-Otu, 2015; Edomwonyi-Otu and Angeli, 2019). The two major classical explanations of the drag reduction (DR) phenomena focus on the viscous effects (Lumley, 1969) and the elastic effects (Tabor and De-Gennes, 1986). Accurate determination of the frictional pressure losses of dilute drag reducing polymer solutions has remained a challenge in many practical applications. Virk (1975) carried out a comprehensive study on drag reduction for aqueous flow and proposed relationships for fanning friction factor which assist other researchers to analyze their results. The performance of his investigation of different polymer solutions showed a trend of maximum drag reduction asymptote in all cases.

Mowla and Naderi (2004) used the experimental data obtained from different operating conditions to propose a mechanistic model for predicting the DR by polymer in two-phase flow. Their model was used for calculating friction and maximum drag reduction as a function of drag reducing agent (DRA) concentration. Sher and Hetsroni (2008) in accordance with the elastic properties of polymer, proposed a mechanistic model for the turbulent drag reduction by additives, and compared their results with Virk's experiment. Chakrabartiet al., (2005) used the ordinary two-fluid model to confirm the interfacial shape in segregated flow. They confirmed that the interface separating the two phases of the separated flow which was assumed to be planar is usually not flat. Liu et al., (2008) reported their experimental studies on the two-phase oil-water in curved pipes with turbulence promoters and analysed their pressure gradient and holdup data using modified Chakrabarti et al., (2005) correlation to account for the curved interface of the oil-water flow. Their result showed acceptable agreement with the experimental pressure gradients of their study and 
those of Angeli and Hewitt (1998). Sharma et al., (2011) also used the mechanistic models coupled with the total energy of the oil-water system to predict the pressure gradients of separated and dispersed oil-water flow in a smooth pipe. The performance of their developed model was tested against several experimental data and existing models, and found that the model predicted the pressure gradients quite well. Rodriguez and Baldani (2012) developed two additional models for the interfacial friction factor in the two-fluid model with the aim of improving the prediction of the pressure gradients. Their developed models were validated against experimental data, and they showed a favourable performance when compared with existing models. Al-Wahaibi (2012) developed empirical correlation for the prediction of two-phase pressure gradient. This was achieved by using the fanning friction factors obtained from Angeli and Hewitt (1998) pressure gradient data for oil-water separated flow in horizontal acrylic and steel pipes to come up with a power law pressure gradient correlation. He observed that the predicted pressure gradients were in good agreement with some published experimental data. Also, the prediction of the correlation was validated against the two-fluid model and it was found to give a better performance in predicting the pressure gradients in most of the existing works. Edomwonyi-Otu and Angeli (2015) also developed an expression between the interfacial heights of oilwater flow at the pipe centre and those close to the pipe wall that was used in the two-fluid model. Their results showed that the addition of both the interface curvature and the equivalent roughness in the twofluid model improved its predictions of pressure gradients. Abubakar (2016) extended his study to develop an empirical model to predict the pressure gradient for oil-water flow with drag reducing polymer (DRP). The prediction was done using 350 experimental pressure drop data points obtained at maximum drag reductions from different flow conditions. He observed that the empirical model predicted the pressure gradient very accurately than the existing available correlations and mechanistic models. Drag reduction has gained acceptance and has found numerous applications, andit has been suggested for transportation of drinking water in pipes (Edomwonyi-Otu and Adelakun, 2018). The focus of this present study is on developing mathematical correlations that show the dependence of drag reduction in two-phase oil-water flow by natural polymers on mixture Reynold numbers under different flow conditions.
Materials: The drag reducing polymers (DRP) used in this study are guar gum and xanthan gum obtained off the shelf in powdered form from Cardinal Chemical Supplies, Zaria. The test fluids used were oil supplied by Kaduna Refining and Petrochemical Company (KRPC), Kaduna, Nigeria and ordinary tap water. The details experimental set-up and description of experimental procedures have been reported in our earlier work (Dosumu et al., 2018; Dosumu et al., 2019).

Model development: The present correlation adopted the power law procedure similar to that of Abubakar (2016). The correlation was developed by plotting all the maximum drag reduction values obtained at different flow conditions from the two uPVC pipes (12 $\mathrm{mm}$ and $20 \mathrm{~mm}$ ID) against their corresponding Reynolds number for each polymer sample (xanthan gum and guar gum). The performance of the developed correlation was checked using statistical analysis. This was achieved by calculating the Mean Percent Error (MPE), Mean Absolute Percent Error $(M A P E)$ and Root Mean Square Percent Error also known as Percent Standard Deviation (PSD) using data from each pipe diameter and combined experimental data. Equations (1) - (3) were used to determine the $M P E, M A P E$ and $P S D$ respectively (Yusuf, 2011; Abubakar, 2016).

$$
\begin{aligned}
& M P E=\left[\frac{1}{n} \sum_{k=1}^{n} \frac{\mathrm{DR}_{\text {Pred }}-\mathrm{DR}_{\text {Exp }}}{\mathrm{DR}_{\text {Exp }}}\right] X 100 \\
& M A P E=\left[\frac{1}{n} \sum_{k=1}^{n}\left|\frac{\mathrm{DR}_{\text {Pred }}-\mathrm{DR}_{\text {Exp }}}{\mathrm{DR}_{\text {Exp }}}\right|\right] X 100
\end{aligned}
$$

$P S D=\left[\sqrt{\frac{1}{n-1} \sum_{k=1}^{n}\left(\frac{\mathrm{DR}_{P r e d}-\mathrm{DR}_{\text {Exp }}}{\mathrm{DR}_{\text {Exp }}}\right)^{2}}\right] X 100$

The MPE indicates the nature of prediction by the correlation which can either be over prediction if it is a positive value or under prediction if it is a negative value. The MAPE shows the prediction capability of the correlation while the $P S D$ indicates the measure of the spread of the predicted values about the experimental values.

\section{RESULTS AND DISCUSSION}

\section{MATERIALS AND METHODS}


Empirical Correlation for Predicting Drag Reduction with DRP: Figures 1 show the variation of maximum drag reduction values with their corresponding Reynolds number by addition of guar gum and xanthan gum. It can be seen from the figure that the correlation coefficient for predicting maximum drag reductions was generated for the natural gums and expressed by Equation (4).

$\% D R=4 \times 10^{-7} R e^{1.72}$

Comparison of predicted drag reductions with experimental data: Figures $2-5$ show the comparisons of the predicted pressure gradients obtained from the developed correlations with the experimental pressure gradients for different DRP and pipe diameters while Table 1 presents the performance of the developed correlation. The $M P E$ and $M A P E$ of the correlation in the 12-mm ID pipe by guar gum (Figure 2) were 8.01 and $23.46 \%$ respectively while the $P S D$ of the predicted drag reductions from the experimental values was estimated to be $28.49 \%$ of the experimental values (Table 1).

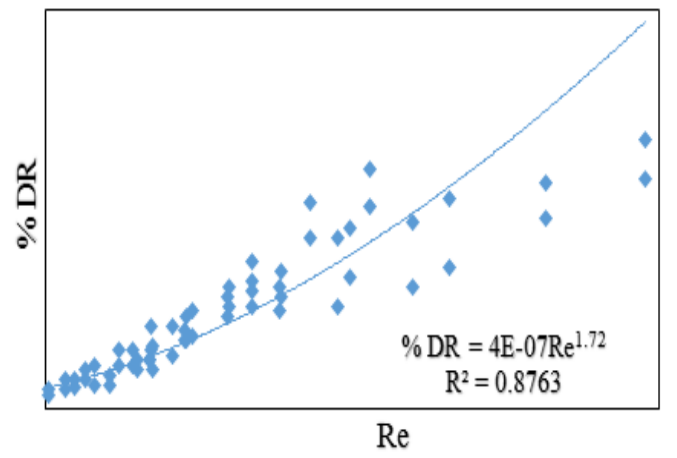

Fig 11: Drag reduction variation of natural gums with Reynolds number

Meanwhile, in the 20-mm ID pipe (Figure 3), the $M P E, M A P E$ and $P S D$ of the correlation were -13.01, 28.62 and $33.16 \%$ respectively as presented in Table 1. It can be seen from the error values that the best agreement in the predicted drag reductions by using guar gum as the DRP was better in 12-mm ID pipe than in $20-\mathrm{mm}$ ID pipe.

Table 1: Statistical data for the accuracy of the developed

\begin{tabular}{|c|c|c|c|c|}
\hline \multicolumn{2}{|c|}{ Data Source } & MPE & MAPE & PSD \\
\hline \multirow[t]{2}{*}{$\overline{\text { GG }}$} & $12 \mathrm{~mm}$ ID & 8.01 & 23.46 & 28.49 \\
\hline & $20 \mathrm{~mm} \mathrm{ID}$ & -13.01 & 28.62 & 33.16 \\
\hline \multirow[t]{2}{*}{ XG } & $12 \mathrm{~mm} \mathrm{ID}$ & -10.45 & 19.51 & 22.47 \\
\hline & $20 \mathrm{~mm} \mathrm{ID}$ & -21.82 & 27.31 & 30.71 \\
\hline \multirow[t]{2}{*}{ Overall } & GG & -2.50 & 26.04 & 30.37 \\
\hline & $X G$ & -4.84 & 11.71 & 18.53 \\
\hline
\end{tabular}

Figures 4 and 5 present the comparison of the predicted drag reductions with the experimental drag reductions by xanthan gum in the $12-\mathrm{mm}$ and $20-\mathrm{mm}$ ID pipes respectively. The correlation produced $M P E$ of $-10.45 \%$, MAPE of $19.51 \%$ and PSD of $22.47 \%$ in the 12-mm ID pipe while MPE of $-21.82 \%, M A P E$ of $27.31 \%$ and $P S D$ of $30.71 \%$ were produced by the correlation in the $20-\mathrm{mm}$ ID pipe. This means that the agreement between the predicted and experimental drag reductions was also better in the 12-mm ID pipe than in the 20-mm ID pipe.

For the combined prediction, the MPE, MAPE and $P S D$ of the correlation for guar gum were -2.50 , 26.04 and $30.37 \%$ respectively while for xanthan gum, the MPE, MAPE and PSD of the predicted drag reductions from the experimental values was estimated to be $-4.87,11.71$ and $18.53 \%$ of the experimental values respectively (Table 1). The agreement of the predicted drag reductions with all the experimental drag reductions was not very far from the best agreement recorded in the individual pipe for both DRP tested. This result shows that the model can be used to predict data accurately in different systems.

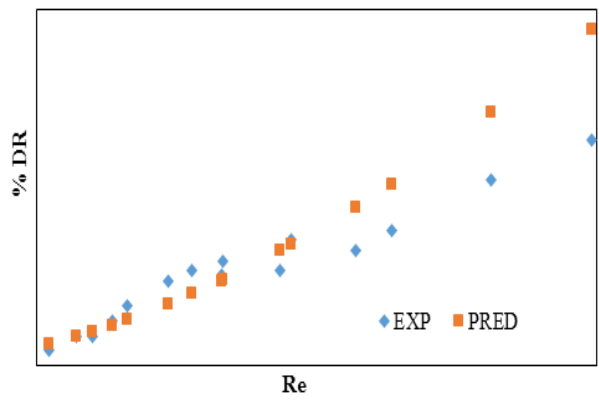

Fig 2: Experimental and predicted drag reductions of guar gum against Reynolds number in 12-mm ID pipe

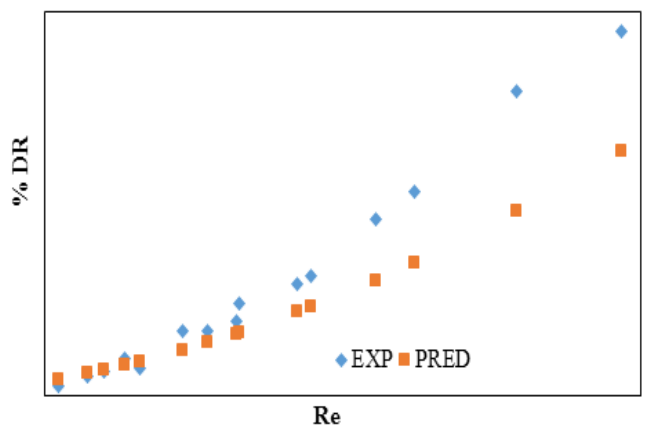

Fig 3: Experimental and predicted drag reductions of guar gum against Reynolds number in 20-mm ID pipe 


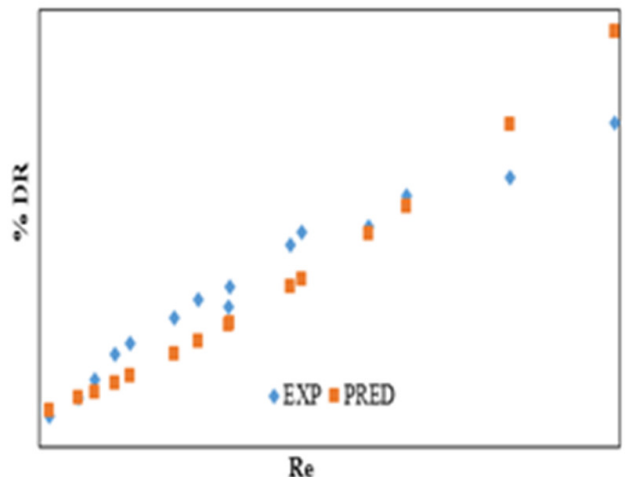

Fig 4: Experimental and predicted drag reductions of xanthan gum against Reynolds number in 12-mm ID pipe

Conclusion: Empirical models were developed for the prediction of drag reduction for oil-water flow with DRPs in horizontal pipes. The models accurately predict the drag reduction across the horizontal pipes. The best agreement between the predicted and experimental drag reductions was better in the $12-\mathrm{mm}$ ID pipe than in the $20-\mathrm{mm}$ ID pipe.

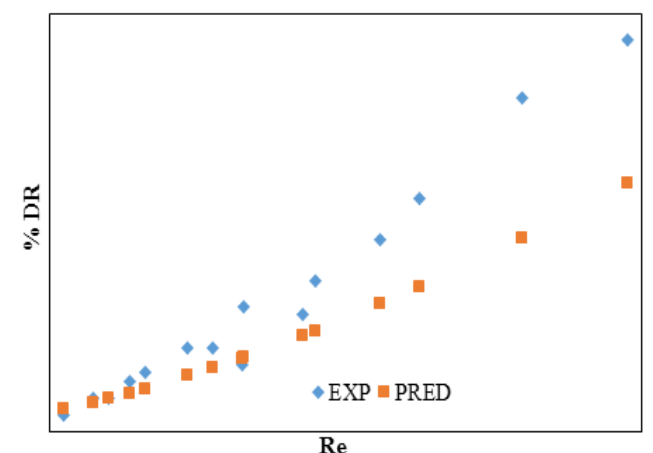

Fig 5: Experimental and predicted drag reductions of xanthan gum against Reynolds number against in 20-mm ID pipe

Acknowledgement: The Authors wish to acknowledge the technical and financial support of the Department of Chemical Engineering and the members of the Multiphase Flows and Separation Systems Research Group, Ahmadu Bello University, Zaria, Nigeria.

\section{REFERENCES}

Abubakar, A (2016). Study of Oil-Water Flow with Drag-Reducing Polymer in Different Pipe Inclinations and Diameters. PhD Thesis. Sultan Qaboos University, Oman.

Angeli, P; Hewitt, G (1998). Pressure Drop Measurements in Oil and Water Prewetted Pipes. In: Proceedings of the International Symposium on Liquid-Liquid Two-Phase Flow and Transport Phenomena, Antalya, Turkey, p.27 -
31.

Al-Wahaibi, T (2012). Pressure Gradient Correlation for Oil-Water Separated Flow in Horizontal Pipes. J. Exp. Therm. Flu. Sci. 42: 196 - 203.

Chakrabarti, DP; Das, G; Ray, S (2005). Pressure Drop in Liquid-Liquid Two-Phase Horizontal Flow: Experimental and Prediction. J. Chem. Eng. Technol. 28(9): 1003 - 1009.

Dosumu, AI; Edomwonyi-Otu, LC; Abubakar, A; Yusuf, N (2018). Effectiveness of Natural Gums as Drag Reducting Agent in Oil-Water Flows. Nig. J. Mat. Sci. Eng. 8: $14-19$.

Dosumu, AI; Edomwonyi-Otu, LC; Abubakar, A; Yusuf, N (2019). Drag Reduction Performance of Natural Gums in Oil-Water Flow Through Pipes of Different Diameters. Res. J. Eng. Environ. Sci. 4(1): In press.

Edomwonyi-Otu, LC (2015). Drag Reduction in OilWater Flows. PhD Thesis. University College, London.

Edomwonyi-Otu, LC; Angeli, P, (2015). Pressure Drop and Holdup Predictions in Horizontal OilWater Flows for Curved and Wavy Interfaces. $J$. Chem. Eng. Res. Des. 93: 55 - 65.

Edomwonyi-Otu, LC; Angeli, P (2019). Separated Oil-Water Flows with Drag Reducing Polymers. J. Exp. Therm. Flu. Sci. Elsevier publication. 102: 467 - 478 .

Edomwonyi-Otu, LC; Adelakun, DO (2018). Effect of Heavy Molecular Weight Polymer on Quality of Drinking Water. Mat. Tod. Comm. Elsevier publication. 15: $337-343$.

Edomwonyi-Otu, LC; Chinaud, M; Angeli, P (2015). Effect of DragReducingPolymeron HorizontalLiquid-LiquidFlows. J. Exp. Therm. Flu. Sci. Elsevier publication. 64: 164- 174.

Jiri, M; Jacqyes, LZ (1997). "Differences in the Flow Behaviours of Polymeric and Cationic Surfactant Drag-Reducing Additives", J. Indust. Eng. Chem. Res. 36: 5483 - 5487.

Kulmatova, D (2013). Turbulent Drag Reduction By Additives. PhD Thesis. University of Amsterdam.

Liu, Y; Zhang, H; Wang, S; Wang, J (2008). Prediction of Pressure Gradient and Holdup in 
Small Eötvös Number Liquid-Liquid Segregated Flow. Chin. J. Chem. Eng. 16(2): $184-191$.

Lumley, JL (1969). Drag Reduction by Additives, Ann. Rev. Flu. Mech. 364 - 367.

Mowla, D; Naderi, A(2004). Effects of Polymer Solutions on Drag Reduction in Horizontal Pipe Two-Phase Flow. In: proceedings of the 9th Iranian Chemical Engineering Congress (IChEC9), Iran University of Science and Technology (IUST), p.31 - 45 .

Rodriguez, OMH; Baldani, LS (2012). Prediction of pressure gradient and holdup in wavy stratified liquid-liquid inclined pipe flow. J. Pet. Sci. Eng. $140-151$.

Sharma, A; Al-Sarkhi, A; Sarica, C; Zhang, HQ
(2011). Modeling of Oil-Water Flow Using Energy Minimization Concept. Int'l. J. Multi. Fl. 37(4): $326-335$.

Sher, I; Hetsroni, G (2008). A Mechanistic Model of Turbulent Drag Reduction by Additives. $J$. Chem. Eng.Sci. 63: 1771 - 1778.

Tabor, M; De-Gennes, PG (1986). A Cascade Theory of Drag Reduction. J. Europhys. Lett. 2: 519 522.

Yusuf, N; Al-Wahaibi T; Al-Wahaibi YM; Al-Ajmi A; Olawale AS; Mohammed IA (2011). Effect of Pipe Diameter on the Efficiency of Drag Reducing Polymer in Horizontal Oil-Water Flows. In: $15^{\text {th }}$ BHR Group Multiphase Production Technology International Conference, Elsevier BV Cannes, France, p.71- 85 . 